\title{
Preface and acknowledgement
}

This book grew out of discussions with Dr. Rainer Moufang, my long-time friend from the Max Planck Institute for German and International Intellectual Property (The institute has been renamed as the Max Planck Institute for Intellectual Property, Competition and Tax Law). On a cold, quiet afternoon in Munich in 2006, we sat in his office discussing the need for a comprehensive review of fundamental and contemporary patent issues as they relate to the protection of both traditional and new technologies. We envisioned a book that would appeal to both academics and practitioners, and we selected experts from three major patent jurisdictions - the United States, Europe and Japan who could write on each topic. Although we granted these authors complete freedom with regard to writing style, we strongly encouraged them to analyze their topics from the comparative law perspective.

Given the opportunity to edit such a book, the first person I would wish to work with is Dr. Moufang, and we originally planned to divide responsibility for the topics while jointly editing the chapters. Unfortunately Dr. Moufang's busy work schedule, along with his family responsibilities, made it impossible for him to participate. Nonetheless, I owe him a huge debt for his insightful topic suggestions and his recommendations of experts from the European Patent Office.

I would also like to thank Professor Jeremy Phillips for giving me the opportunity to edit this book, one of the volumes in a series for which he serves as the general editor. Professor Phillips not only agreed to contribute a chapter but also suggested additional authors from the UK, thereby giving the book an approach to patent protection from a common law tradition that is different from the common law tradition that the USA follows.

I also would like to thank my assistant, Ms Ruth Beardsley for providing prompt secretarial support and my former research assistants, particularly Ms Juri Yoshida, who oversaw the entire editing process, communicating with authors and managing deadlines. Finally, I would like to thank my husband, Hisato, for his forbearance and continuous support of my work.

Toshiko Takenaka 